\title{
REVIEWS
}

\section{A Comparison of Selected Regenerative Materials Used in the Management of Pulp Diseases - Review of the Literature}

\section{Porównanie wybranych materiałów regeneracyjnych stosowanych w leczeniu chorób miazgi zębów - przegląd piśmiennictwa}

Department of Conservative and Pediatric Dentistry, Wroclaw Medical University, Wrocław, Poland

A - research concept and design; $\mathbf{B}$ - collection and/or assembly of data; $\mathbf{C}$ - data analysis and interpretation;

$\mathbf{D}$ - writing the article; $\mathbf{E}$ - critical revision of the article; $\mathbf{F}$ - final approval of article

\begin{abstract}
The authors present a group of regenerative materials recommended for the treatment of deep caries, pulp exposure, endodontic treatment of immature teeth involving apexogenesis and apexification, and management of internal resorption and chronic periapical inflammations. Biomaterials which demonstrate biocompatibility, expressed by direct integration with dentine on a molecular level, also stimulate the formation of secondary and reparative dentine by odontoblasts. Calcium hydroxide is the oldest and has been the most widely used biomaterial since the $19^{\text {th }}$ century. However, due to some inconveniences experienced during treatment with this material, modern odontotropic materials like Mineral Trioxide Aggregate (MTA) or Biodentine are more frequently and more preferably used. New materials like MTA and Biodentine make it possible to develop new protocols of treatment and create opportunities for their successful results. Biodentine, in comparison with MTA, seems to be easier to prepare and apply, with a much shorter setting time.

However it should be emphasized that observations of the performance of these new regenerative materials are relatively limited, so further research is required to confirm their long term performance and usefulness and to formulate reliable conclusions (Dent. Med. Probl. 2015, 52, 4, 485-490).
\end{abstract}

Key words: dental materials, MTA, Biodentine.

Słowa kluczowe: materiały stomatologiczne, MTA, Biodentyna.

Bioactive materials constitute the group of products which both in vitro and in vivo do not harm vital cells and minimally affect the immune system. In dental therapies these materials, presenting biocompatibility expressed by direct integration with dentine on a molecular level, are tolerated by pulpal cells and demonstrate the capability to stimulate the formation of secondary and reparative dentine (odontotropic action) [1-4].

For many years calcium hydroxide $\mathrm{Ca}(\mathrm{OH})_{2}$ has been one of the most recognizable and most widely used of odontotropic materials. It was introduced into dentistry in the $19^{\text {th }}$ century and since that time it has been commonly used in various indications, especially due to its strong alkalizing, antibacterial, antinflammatory potential as well as its capacity to stimulate pulpal regenerative processes [5-10]. The mechanism of action of calcium hydroxide products is based on its ability to dissociate in aqueous solutions into free $\mathrm{Ca}^{2+}$ ions and hydroxyl ions which activate many chemical reactions in contact with vital tissue as well as provide a highly alkaline environment with $\mathrm{pH}$ of approximately 12.5 [5-10]. Free hydroxyl ions show enormous reactivity with many various biomolecules. They have an influence on the activity 
of alkaline phosphatase and ATP-ases which are the catalysts of odontotropic processes and which are able to neutralize some mediators of the inflammatory reactions such as hydrolases or lactic acid. They also initiate differentiations of mesenchymal cells into fibroblasts, cementoblasts and osteoblasts. The extremely high $\mathrm{pH}$ provides an alkaline environment triggering bacteriocidic and bacteriostatic properties of the preparations. The intracellular action leads to irreversible damage of DNA, proteins, enzymes and lipids within bacterial cells and hydrolysis of the lipopolysaccharides in their cytoplasmatic membranes [6, 8-11]. Absorption of carbon dioxide from the environment potentiates the bactericidal effects of this material, additionally exerting its negative impact on anaerobe microorganisms [9, 12]. Calcium hydroxide is also capable of denaturing proteins, eliminating the remnants of necrotic pulp. It also demonstrates long term anti-inflammatory properties through inhibition of enzyme phospholipase, activation of Ca canals and hygroscopic action $[6,9,10,12]$. Other significant advantages of this material are low toxicity and allergenic potential and resorbability of the material inadvertently deposited behind the apex during endodontic treatment $[6,8,11]$. The relatively low costs, flexible consistency and availability of various formulations are not without significance. Depending on the manner of setting, these materials are divided into two main groups: non-setting solutions which release ions immediately and constantly and setting pastes with delayed and periodic release of ions. The above-mentioned advantages contribute to the wide range of its use in dentistry, among others in the treatment of deep caries, pulp exposures, endodontic treatment of immature teeth requiring apexogenesis and apexification, different types of internal resorption and chronic apical lesions $[6-9,12,13]$. Unfortunately, the coinciding drawbacks of calcium hydroxide preparations occasionally exclude their use or increase the risk of unfavorable outcomes. This includes a high sensitivity to moisture, causing its dissolution and washing out, lack of adhesion to the dentine or to bonding systems which is responsible for microleakage and post treatment sensitivity $[6,7,10]$. The relatively low diffusion coefficient of calcium hydroxide, impeding the achievement of high concentrations of the ions in tissues, and the significant decrease of $\mathrm{pH}$ from 12.5 to 8.0 in 2-3 weeks cause prolongation of the treatment of contaminated root canals which in turn may weaken the tooth and increase the risk of fracture of the crown. The loss of restoration in the coronal part of the tooth, discolorations of hard tissues and reinfections were also observed after endodontic treatment $[6,11,12,14]$. Numerous studies $[5,9$, $12,13]$ have revealed that dentinal bridges formed as a result of odontotropic processes are irregular and quite thin. They frequently include so-called tunnels (gaps), which may predispose the patient to infection of the pulp. Materials based on calcium hydroxide are not indicated for the treatment of immature permanent teeth if there are remnants of vital pulp within the canal, due to the risk of formation of a layer of highly mineralized tissue which obstructs the root canal leading to the inhibition of regenerative processes $[8,9,12]$. Calcium hydroxide may also harm Hertwig sheat cells resulting in the loss of their capability to stimulate the transformation of undifferentiated cells into odontoblasts $[15,16]$.

Keeping in mind the potential complications and some inconveniences related to treatment with the use of calcium hydroxide products, practitioners nowadays increasingly prefer modern odontotropic materials which present the properties outperforming those of previously used materials. They include primarily Mineral Trioxide Aggregate (MTA) and Biodentine.

Mineral Trioxide Aggregate (MTA) was introduced into dentistry in early 1990 for prompt obturation of the apical part of root canals and seal closure of perforations in the canal walls which occurred during endodontic treatment. This is a mixture of aluminum, calcium, magnesium, sodium and potassium oxides with bismuth oxide and calcium phosphate. The composition is similar to Portland cement enhanced with about $20 \%$ of bismuth oxide, added for the effect of radiographic contrast (comparable to gutta-percha) and with a diminished content of heavy metals and gypsum at the same time, which delay its setting time $[6,17-20]$. The material is manufactured in the form of hydrophilic powder which hardens in the presence of water, forming a colloidal consistency compared to wet sand. Two types of MTA are available: esthetic and non discoloring white MTA - White Mineral Trioxide Aggregate (WMTA) and gray MTA - Gray Mineral Trioxide Aggregate (GMTA) with the addition of ferric oxide which may cause discoloration of treated teeth and periapical tissue, but it presents greater mechanical strength [6, 20-22]. Preparation of this material for use involves mixing the powder with liquid (distilled water) for approximately $30 \mathrm{sec}-$ onds to obtain a homogenous material for immediate application. Then the treated tooth should be closed with adequately sealed temporary obturation (glassionomer or IRM enhanced with resins). The deposited material should be covered by a wet cotton ball for at least 6 hours. MTA hardens in about 3-4 hours from the time the components 
were mixed and then, after a hard barrier in the area of application has been obtained, further treatment may follow $[6,22,23]$. The hydrophilic nature of the metal oxide particles makes it possible to set the material in the presence of organic fluids such as blood or saliva [19, 22-25]. The mechanism of action of MTA is probably based on providing very high $\mathrm{pH}$ in a short time (10.5 increasing to 12.5 in 3 hours) and alkalizing the local environment. This inhibits microorganisms and inflammatory reactions in vital pulp as well as stimulates remineralizing processes $[18,19,22]$. According to Reyes-Carmona et al. [26], MTA promotes the formation of regenerative dentine through its alkalizing potential and precipitation of apatites in the acute phase of the inflammation process. Additionally, during the reaction of setting, calcium oxide is released, which subsequently reacts with tissue fluids and forms calcium hydroxide [20]. This activates odontotropic processes by stimulation of osteoblasts, providing biologically active substrates and the production of cytokines responsible for bone metabolism, improving the bone cells' adherence to the material, enhancing the proliferation of fibroblasts and the production of alkalic phosphatase [11, 17, 20, 27, 28]. Mineral Trioxide Aggregate presents antibacterial properties (also against anaerobes and Enterococcus faecalis) as well as antifungal. Ferk et al. [29] proved the strongest action against colonies of Streptococcus mutans, Streptococcus mitis and Lactobacillus acidophilus. Al-Kahtani et al. [30] analyzed the relationship between the thickness of a layer of Mineral Trioxide Aggregate and microbial microleakage. They revealed that only a layer of $5 \mathrm{~mm}$ or more is adequately sealed and provides sufficient protection against an infection of Actinomyces viscosus and Staphylococcus. Several studies [17, 20, $25,31]$ have confirmed the biocompatibility of MTA excluding its potential cytotoxic, genotoxic or mutagenic effect on vital cells, especially pulpal cells. MTA does not cause any disturbances in their differentiation or functioning. For these reasons, post treatment sensitivity is not observed and inflammatory reactions within the pulp occur quite rarely. Łuczaj-Cepowicz et al. [19] showed $100 \%$ effectiveness of MTA in direct pulp capping obtained by the formation of a hard barrier with a simultaneous lack of pulp inflammation. It has been observed that dentinal bridges stimulated by MTA are formed more quickly and are thick, compact, homogenous, more regular in their structure and free of so-called tunnel effects which are typical with the use of calcium hydroxide $[13,15,20$, 28]. MTA is characterized by very good marginal seal due to its excellent adaptation to the hard tissues, high compressive strength within the range of $70 \mathrm{MPa}$ and insolubility in fluids [18, 19, 27, 32]. Additionally, the study by Wilkoński et al. [17] and Camilleri et al. [32] reveal deposition of Ca-P complexes on the surface of MTA and formation of early forms of apatites in their presence. This has a favorable impact either on the processes of apexification or obtaining an adequate marginal seal. According to the research conducted by Yildirim et al. [24], the smear layer does not affect the seal of MTA, hence there is no need for its removal before application of Mineral Trioxide Aggregate. Among the disadvantages of MTA, one can list the long setting time which lasts minimum 4 to 6 hours, complicated mode of storage, preparation and application and high cost $[6,19,22,23,31]$. Manufacturers pay special attention to the manner of storage because the material absorbs ambient moisture, as well as to the strict adherence to the instructions in the matter of powder to liquid ratios. Practitioners complain of difficulties with the application of MTA due to its hard-to-manage consistency of wet sand, which forces them to use additional instruments: plastic or metal carriers (Endodontic Carrier, p-MTA Pistolet-Kit), potential discoloration of the teeth (with the use of Grey MTA) and necessity to postpone the final procedures until the subsequent visit. MTA is successfully used in various aspects of pulpal pathology. Several studies have confirmed its effectiveness in direct pulp capping, closure of perforations, obturation of root canals with wide apical foramina, apexogenesis and apexification as well as in the treatment of internal and external resorption $[6,18,19,22,25,28]$.

Another increasingly popular alternative for calcium hydroxide and also MTA is the biocompatible material Biodentine. This is the first bioactive cement which can entirely substitute dentine within the crown and the root $[4,33]$. The material is prepared ex tempore from precise amounts of powder deposited in a capsule and liquid in the pipette. The composition of the powder resembles Portland cement and its main components are tricalcium silicate $\left.(3 \mathrm{CaO} \mathrm{SiO})_{2}\right)$ and dicalcium silicate $\left(2 \mathrm{CaO} \mathrm{SiO}_{2}\right)$, responsible for setting. Calcium carbonate plays the role of a filler whereas zirconium dioxide provides radiographic contrast. The liquid is an aqueous solution of calcium chloride $\left(\mathrm{CaCl}_{2} 2 \mathrm{H}_{2} \mathrm{O}\right)$, which acts as a catalyst, accelerating the setting reaction $[27,34,35]$. The application powder is mixed with the liquid for $30 \mathrm{sec}-$ onds in a mixing machine. The result of this process is a ready-to-use hydrated calcium silicate gel - $\mathrm{CSH}$ and calcium hydroxide. The working time is about 6 minutes, and the setting time lasts another 6 minutes. After this time, the material becomes hard and the next step of the procedure may 
be executed [34-36]. According to the manufacturer, the final hardness occurs about 30 days after application. The mechanism of action is based on the release of calcium hydroxide, either during the setting reaction or a long time after hardening and the immediate local provision of very high $\mathrm{pH}$ $(\mathrm{pH}=12.5)$ [36]. This stimulates the vital pulp to form a secondary and reparative dentine, and initiates differentiation of the cells within the pulp and periapical tissues $[4,34,35]$. Dentinal bridges stimulated by Biodentine, similarly to the use of MTA, are characterized by increased thickness, mechanical strength and reduced permeability $[4,16,35,36]$. Studies have revealed that Biodentine, like MTA, does not demonstrate significant cytotoxic, genotoxic or mutagenic effects $[4,34-$ 36]. The cytotoxicity of Biodentine ranges from $10 \%$ (in the first day) to 7\% (after 7 days) and is similar to that of MTA [35]. Comparably to other agents used in pulp therapy, Biodentine very rarely induces adverse reactions in the form inflammation of the pulp or periapical tissues $[26,36]$. High alkaline $\mathrm{pH}(\mathrm{pH}=12.5)$ facilitates binding with the dentine without the necessity of use of acids and bonding systems which may provoke posttreatment sensitivity $[37,38]$. This action is called surface conditioning of the enamel and dentine and relies on the dissolution of organic matter in peritubular spaces and exposure of tubular orifices. This leads to the formation of mineralized tags within the dentinal tubules resulting in a dynamic and biomimetic bonding of the material with dental hard tissues [38].

Observations obtained in several studies [17, $27,31]$ suggest a conclusion that Biodentine demonstrates physical properties similar to or even better than MTA and definitely superior to calcium hydroxide. They include an excellent and long-lasting marginal seal, high dimensional stability and optimal mechanical performance approximate to those of dentine (compressive strength $-220 \mathrm{MPa}$, microhardness - $60 \mathrm{VHN}$, modulus of elasticity - $22 \mathrm{GPa}$ ) [35, 38]. The crush strength is $34 \mathrm{MPa}$ after two hours and is comparable to the parameters of glass ionomer cements [37]. Research has shown [32] a high resistance of Biodentine against acids in comparison to the other cements. The lack of free monomers minimizes the potential for allergic reactions while the ease of application and short setting time allow efficient performance of the procedure. This is especially significant in biological treatments, when the possibility of closure of the cavity during one visit diminishes the risk of complications and increases the chances of a successful outcome. The advantageous properties of Biodentine have led to its wide use in restorative dentistry and endodontics. The indications for use are: direct and indirect pulp capping, closure of perforations, obturation of the root canals with wide apical foramina, apexogenesis and apexification, and treatment of internal and external resorption $[25,33,36]$. The high biocompatibility, low risk of inflammatory reaction of vital tissues, regenerative capacity, short setting time and consistency allowing easy application make this material a valuable alternative to conventional calcium hydroxide materials or MTA. However it has been observed that temporary restorations made with Biodentine demonstrated partial loss of marginal integrity after 3 to 6 months, which could lead to a defective marginal seal and microleakage $[34,37,38]$. The reason might be the low quality of the entire restoration or its finishing. Manufacturers recommend shaping of the material in the cavity after at least 6 minutes since mixing. Excessive condensation, shaping and modeling may damage the crystalline microstructure and disturb the setting reaction or even make it impossible. The material should be applied with the use of carriers and the exertion of slight pressure. The rotational instruments are not recommended as well as the polishing of the restoration. The patient should be asked not to overload the restored tooth during the first few hours and to avoid hot, very cold and sour food. Koubi et al. [34] reported abrasive features marked in $25 \%$ of the restoration after 6 months and 30\% in the period of 6 to 12 months. Some authors $[35,38]$ recommend the use of two visit procedures with the removal of the upper layer of Biodentine after 1 week to 6 months and replacing it with glass ionomer or composite. While planning the use of Biodentine, its unsatisfying white opaque shade should be kept in mind as well as its high cost, exceeding that of conventional material like calcium hydroxide. In contrast to MTA, which sets in the presence of physiological fluids, Biodentine is highly sensitive to moisture during the initial phases of setting [32]. The studies of Lipski et al. [27] and Wilkoński et al. [17], which compared the ability of MTA and Biodentine to seal the root canals, revealed that they both lead to a similar effect. The availability of odontotropic materials makes it possible to perform various procedures allowing there to remain vital and healthy pulp. This kind of treatment is always related to a high risk and the final outcome depends on many additional factors. The oldest and best-known material, calcium hydroxide, apart from its undeniable advantages, also presents many drawbacks, lowering its value and contributing to uncertain outcomes. New materials like MTA and Biodentine make it possible to develop the new protocols of treatment and give chances for their successful results. Biodentine in 
comparison with MTA seems to be easier for preparing and application with a much shorter setting time. However it should be emphasized that observations of the performance of these new re- generative materials are relatively limited, so further research is required to confirm their long term performance and usefulness and to formulate reliable conclusions.

\section{References}

[1] Koliniotou-Koumpia E., Tziafas D.: Pulpal responses following direct pulp capping of healthy dog teeth with dentine adhesive systems. J. Dent. 2005, 33, 639-647.

[2] Andelin W.E., Shabahang S., Wright K., Torabinejad M.: Identification of hard tissue after experimental pulp capping using dentin sialoprotein (DSP) as a marker. J. Endod. 2003, 29, 646-650.

[3] Camilleri J., Montesin F.E., Papaionnnou S., McDonald F., Pitt Ford T.R.: Biocompatibility of two commercial forms of mineral trioxide aggregate. Int. Endod. J. 2004, 37, 699-704.

[4] Laurent P., Camps J., Aвout. I.: Biodentine ${ }^{\mathrm{TM}}$ induces TGF-b1 release from human pulp cells and early dental pulp mineralization. Int. Endod. J. 2012, 45, 439-448.

[5] Tran X.V., Gorin C., Baroukh W.B., Pellat B., Decup F., Opsahl Vital S., Chaussain C., Boukpessi T.: Effect of a calcium-silicate-based restorative cement on pulp repair. J. Dent. Res. 2012, 91, 1166-1171.

[6] Piesiak-Pańczyszyn D., Pregiel B., Fita K.: Endodontic treatment of permanent teeth with incomplete root formation in the dependence from used material. Implantoprot. 2010, 11, 1, 38-43 [in Polish].

[7] Pietrzycka K., Pawlicka H.: Two appointments treatment of teeth with infected root canals and periapical inflammation using calcium hydroxide - status report. e-Dentico 2011, 29, 1, 76-84 [in Polish].

[8] Soares J., Santos S., Cesar C., Silva P., Sa M., Silveira F., Nunes E.: Calcium hydroxide induced apexification with apical root development: a clinical case report. Int. Endod. J. 2008, 41, 710-719.

[9] Postek-Stefańska L., Brzoza M., Kalacinska J.: The use of calcium hydroxide in dentistry - review of the literature. Stomatol. Współcz. 2004, 11, 2, 50-55 [in Polish].

[10] Pawińska M., Skrzydlewska E.: The release of calcium and hydroxide ions from calcium hydroxide preparates. Czas Stomatol. 2004, 47, 715-720 [in Polish].

[11] Rafter M.: Apexification - a review. Dent. Traumatol. 2005, 21, 1-8.

[12] Pietrzycka K.: Calcium hydroxide in treatment of infected root canals. Review of the literature. e-Dentico 2007, 13, 1, 78-81 [in Polish].

[13] Kierat A., Laszczyńska M., Kowalska E., Weyna E.: Comparison of the effect of mineral trioxide aggregate and calcium hydroxide in biological treatment of pulp of permanent teeth and in cell culture. Ann. Pomer. Med. Univ. 2010, 56, 2, 89-96 [in Polish].

[14] Kawamoto R., Kurokawa H., Takubo C., Shimamura Y., Yoshida T., Miyazaki M.: Change in elastic modulus of bovine dentine with exposure to a calcium hydroxide paste. J. Dent. 2008, 36, 959-964.

[15] Thomson A., Kahler B.: Regenerative endodontics - biologically-based treatment for immature permanent teeth: a case report and review of the literature. Aust. Dent. J. 2010, 55, 446-452.

[16] Camilleri J., Sorrentino F., Damidot D.: Investigation of the hydration and bioactivity of radiopacified tricalcium silicate cement, Biodentine and MTA Angelus. Dent. Mater. 2013, 29, 580-599.

[17] Wilkoński W., Kwapińska H., Jamróz-Wilkońska L., Mendel P., Suchodolski Ł., Krupiński J., OpiŁa J.: Comparison of sealing ability of Grey MTA Angelus, Tech Biosealer Apex and Biodentine in permanent teeth with incomplete root formation. Magazyn Stomatol. 2012, 22, 7-8, 90-95 [in Polish].

[18] ĆWikLak K., Szczepańska J.: The use of MTA in permanent teeth with incomplete root formation - review of the literature. Nowa Stomatol. 2012, 17, 1, 19-23 [in Polish].

[19] Łuczaj-Cepowicz E., Marczuk-Kolada G., Waszkiel D.: The possibilities of clinical application of new material mineral trioxide aggregate (MTA) - review of the literature. Nowa Stomatol. 2006, 11, 4, 165-169 [in Polish].

[20] Hilt A., SzydŁowska-Walendowska B.: Indirect pulp capping in permanent teeth using MTA in patients of developmental age. e-Dentico 2011, 29, 1, 86-93 [in Polish].

[21] Asgary S., Parirokh M., Eghbal M.J., Brink F.: Chemical differences between white and grey mineral trioxide aggregate. J. Endod. 2005, 31, 101-104.

[22] Mente J.: Mineral Trioxide Aggregate. Indication and practical application on the basis of specific cases. Endodoncja.pl 2009, 4, 229-241 [in Polish].

[23] Simon S., Rilliard F., Berdal A., Machtou P.: The use of mineral trioxide aggregate in one-visit apexification treatment: a prospective study. Int. Endod. J. 2007, 40, 186-197.

[24] Yildirim T., Er K., Taşdemir T., Tahan E., Buruk K., Serper A.: Effect of smear layer and root-end cavity thickness on apical sealing ability of MTA as a root-end filling material: A bacterial leakage study. Oral Surg. Oral Med. Oral Pathol. Oral Radiol. Endod. 2001, 109, 67-72.

[25] Staszczyк M., Wróblewska M., Zarzecka J.: Use of regenerative endodotics in treatment of permanent teeth with incomplete roots - review of the literature. Poradnik Stomatol. 2011, 8, 300-303 [in Polish].

[26] Reyes-Carmona J.F, Santos A.R.S, Figueiredo C.P, Felippe M.S, Felippe W.T, Cordeiro M.M.: In vivo host interactions with mineral trioxide aggregate and calcium hydroxide: inflammatory molecular signaling assessment. J. Endod. 2011, 37, 1225-1235.

[27] Lipski M., Nowicka A., Górski M., Dura W., Lichota D.: Comparison of sealing ability of MTA and Biodentine used to reverse filling of root canals. Magazyn Stomatol. 2012, 22, 6, 82-85 [in Polish]. 
[28] Czarnecka B., Coleman N.J., Shaw H., Nicholson J.W.: The use of mineral trioxide aggregate in endodontics - status report. Dent. Med. Probl. 2008, 45, 5-11 [in Polish].

[29] Ferk S., Simeon P., Matijevic J.: Antibacterial effect of mineral trioxide aggregate and amalgam. Acta Stomatol. Croat. 2011, 45, 8-12.

[30] Al-Kahtani A., Shostad S., Schifferle R., Bhambhani S.: In vitro evaluation of microleakage of an orthograde apical plug of mineral trioxide aggregate in permanent teeth with simulated immature apices. J. Endod. 2005, 31, $117-119$.

[31] Grech I., Mallia B., Camilleri J.: Investigation of the physical properties of tricalcium silicate cement-based root-end filling materials. Dent. Mater. 2013, 29, 20-28.

[32] Camilleri J., Kralj P., Veber M., Sinagra E.: Characterization and analysis of acid extractable and leached trace elements in dental cements. Int. Endod. J. 2012, 45, 737-743.

[33] Bakapoulou A., Авоut I.: Biodentine, a promising bioactive material for the preservation of pulp vitality in restorative dentistry. Case Studies Collection Septodont. 2013, 5, 4-10.

[34] Koubi G., Colon P., Franquin J.C., Hartmann A., Richard G., Faure M.O., Lambert G.t.: Clinical evaluation of the performance and safety of a new dentine substitute Biodentine in the restoration of posterior teeth. A prospective study. Clin. Oral Investig. 2013, 17, 243-249.

[35] Nowicka A., Lipski M., Postek-Stefańska L., Wysoczańska-Jankowicz I., Lichota D., Sporniak-Tutak K., BuCZKowsKa-RADlińsKa J.: Indirect pulp capping in permanent teeth using Biodentine. Magazyn Stomatol. 2012, 22, 4, 30-37 [in Polish].

[36] Dammaschke T.: Biodentin a new bioactive cement for direct pulp capping. Case Studies Collection, 2012, 1, 4-8.

[37] Raskin A., Eschrich G., Dejou J., Aвоut I.: In vitro microleakage of Biodentine as a dentin substitute compared to Fuji IILC in cervical lining restorations. J. Adhesive Dent. 2012, 14, 535-541.

[38] Firla M.T.: Direct pulp capping with a bioactive dentine substitute. Case Studies Collection, 2012, 1, 17-21.

\section{Address for correspondence:}

Dagmara Piesiak-Pańczyszyn

Department of Conservative and Pediatric Dentistry

Wroclaw Medical University

Krakowska 26

50-425 Wrocław

Poland

E-mail: dagmara piesiak-panczyszyn@umed.wroc.pl

Conflict of Interest: None declared

Received: 7.05.2015

Revised: 13.06 .2015

Accepted: 15.07.2015 